\title{
Acquired Attenuation of Chemoreceptor Function in Chronically Hypoxic Man at High Altitude
}

\author{
John V. Weil, Edward Byrne-Quinn, Ingvar E. Sodal, Giles F. Filley, \\ and ROBERT F. GROVER
}

From the Department of Medicine, University of Colorado Medical Center, Denver, Colorado 80220

\begin{abstract}
A в S T R A C T To determine whether chronic exposure to hypoxia during adulthood produces alterations in the control of ventilation, measurements of the resting ventilatory response to hypoxia and hypercapnia, as well as ventilatory response to hypoxia during exercise, were carried out in a group of 10 long-term (3-39 yr) nonnative residents of Leadville, Colo. (elevation $3100 \mathrm{~m}$ ). A group of 8 subjects native to Leadville was also studied and 10 low altitude subjects of Denver, Colo. (elevation $1600 \mathrm{~m}$ ) served as controls. Hypoxic ventilatory drive was measured as the shape parameter A of isocapnic $\mathrm{VE}-\mathrm{PAO}_{2}$ curves. In the non-native high altitude resident this parameter averaged $43 \%$ of the value for low altitude controls $(P<0.05)$ denoting a diminished ventilatory response to hypoxia. The degree of attenuation was related to the length of time spent at high altitude. In the high altitude natives the parameter A averaged $9.6 \%$ of control $(P<0.01)$. Similarly hypercapnic ventilatory drive as measured by the slope of the isoxic VE-P $\mathrm{Aco}_{2}$ lines was reduced in the non-native residents to $65 \%$ of control $(P<0.05)$ and in the natives averaged $54 \%$ of control $(P<0.01)$.

In contrast with these findings at rest induction of hypoxia during exercise produced an increase in ventilation comparable to that in the controls in both groups of highlanders.
\end{abstract}

Hence chronic exposure to hypoxia during adulthood in man results in marked attenuation of the ventilatory response to hypoxia at rest and this is a function of the length of exposure to hypoxia. This attenuation of the ventilatory response to hypoxia was associated with a decrease in hypercapnic ventilatory drive. The fact that hypoxic ventilatory drive was almost completely absent while hypercapnic drive was only partially reduced parallels closely the more important role of the peripheral chemoreceptors in mediating ventilatory responses

Received for publication 29 June 1970 and in revised form 2 September 1970. to hypoxia than to hypercapnia. This suggests that the alterations in ventilatory control at altitude are due to failure of peripheral chemoreceptor function.

\section{INTRODUCTION}

Much evidence suggests that chronic hypoxia produces alterations in the control of ventilation in man. It is generally agreed that the ventilatory response to hypoxia is diminished in persons native to high altitude $(1-3)$. However, there is controversy regarding the question of whether hypoxic ventilatory drive is altered in the non-native long-term resident of high altitude. This matter is important because the question of whether attenuation of hypoxic ventilatory drive may be acquired through chronic exposure to hypoxia is essential to understanding the control of breathing in hypoxic disease states in which the exposure to hypoxia begins in adulthood. In the present study the control of breathing was measured in persons native to high altitude and in long-term non-native residents of high altitude. The data indicate that hypoxic ventilatory drive is indeed depressed in non-native residents of high altitude and that the degree of depression is a function of the length of time spent at high altitude. In addition there is an associated milder depression of hypercapnic ventilatory drive.

\section{METHODS}

There were three groups of subjects all of whom were men and all were in excellent health. The control group was comprised of 10 normal men living in Denver, Colo (elevation $1600 \mathrm{~m}$ ). The high altitude subjects lived in the community of Leadville, Colo. (elevation $3100 \mathrm{~m}$ ). Eight were natives between the ages of 29 and $56 \mathrm{yr}$. Ten subjects were non-native long-term residents of Leadville, aged 25-59 yr. All but one of the latter group had come to high altitude in their 3rd or 4th decade. None of the subjects had ever engaged in varsity athletics and none had participated in a formal physical conditioning program. The goals and con- 
duct of the study were explained to all subjects to their granting consent. All studies were performed in our laboratory in Denver, Colo., within 3-15 hr following the subject's departure from high altitude.

Ventilatory drive at rest. A detailed description of this technique has been given by us elsewhere (4). The seated subject breathes through a respiratory valve (Hans $\mathrm{Ru}$ dolph) from which gases are continuously sampled by an infrared $\mathrm{CO}_{2}$ analyzer (Beckman LB-1) and by a fuel cell, rapid oxygen analyzer $(5,6)$. Output from both of these together with information from a pneumotachograph (Fleich) are fed into an on-line PDP-8 computer, the data emerging as continuous, real time oscilloscopic plots of end-tidal oxygen tension, end-tidal carbon dioxide tension, and minute ventilation. The end-tidal oxygen plot is used to guide the manual addition of nitrogen to the inspired air so as to produce a gradual fall in end-tidal oxygen tension from 120 to $40 \mathrm{~mm} \mathrm{Hg}$ over $15-20 \mathrm{~min}$. Output from the carbon dioxide analyzer is also displayed on an oscilloscope and used to guide the manual addition of $100 \% \mathrm{CO}_{2}$ to the inspired gas in amounts sufficient to prevent hypocapnia.

The use of this non-steady-state technique for measuring the ventilatory response to hypoxia with isocapnia is justified by the fact that ventilatory adjustment to a change in alveolar $\mathrm{PO}_{2}$ is complete in $20 \mathrm{sec}$ and the maximal effective $\mathrm{PAO}_{2}$ phase error is $1.2 \mathrm{~mm} \mathrm{Hg}$ higher than actually observed at a given point in time (4). Also the accuracy of the maintenance of isocapnia and a stable $\mathrm{pH}$ has been confirmed by simultaneous arterial studies (4).

Plots of ventilation in relation to $\mathrm{PAO}_{2}$ are hyperbolic. In order to compare curves, a simple empirical equation is used similar to one originally suggested by Lloyd, Jukes, and Cunningham (7). The equation relates ventilation and alveolar $\mathrm{Po}_{2}$ as follows: $\mathrm{VE}_{E}=\mathrm{VE}_{\mathrm{E}_{0}}+\mathrm{A} / \mathrm{PA}_{\mathrm{A}_{2}}-32$ ), where $\mathrm{VE}$ and $\mathrm{PA}_{\mathrm{O}_{2}}$ are minute ventilation in liters per minute STPD and alveolar $\mathrm{Po}_{2}$ in millimeters of mercury, respectively. Parameter $\mathrm{VE}^{0}$ is the asymptote for ventilation obtained by extrapolation and parameter $\mathrm{A}$ determines the shape of the curve such that the higher the value for $A$ the greater the hypoxic ventilatory drive. In practice the curve fitting procedure and evaluation of parameters are accomplished by a time shared GE-400 computer programmed for nonlinear least squares curve fit by the method of Marquardt (8). Questions might be raised concerning the absolute meaning of the parameter A used in this study as a measure of hypoxic drive. In a simple linear situation as the $\mathrm{VE}-\mathrm{PACO}_{2}$ relationship ventilatory drive is traditionally measured as the slope $(\mathrm{S})$, but in a nonlinear relationship as is found in the $\mathrm{VE}-\mathrm{PACO}_{2}$ response a question arises as to what index should be employed as a measure of ventilatory drive. We have used the parameter $A$ because it accurately describes the shape of $\mathrm{VE}-\mathrm{PAO}_{2}$ relationship over a wide range of alveolar oxygen tensions (130-40 $\mathrm{mm} \mathrm{Hg}$ ), which encompasses the levels of hypoxia seen in the majority of persons at high altitude and with hypoxic disease states. Within this range a low value for $\mathrm{A}$ indicates a smaller increase in $\mathrm{VE}$ for any given decrease in $\mathrm{PA}_{0 .}$. It must be emphasized that neither this parameter nor the fitted curves are predictive of ventilatory responses to oxygen tensions outside the observed range. This approach was inaugurated by Lloyd et al. (7) whose parameter $A$ is equal to our $\mathrm{A}$ value divided by $\mathrm{VE}^{0}$.

Hypercapnic ventilatory drive is measured with progressive hypercapnia induced by gradual addition of $100 \% \mathrm{CO}_{2}$ to the reservoir bag such as to increase $\mathrm{PAcO}_{2}$ by $10-15 \mathrm{~mm}$ $\mathrm{Hg}$ in about $10-15 \mathrm{~min}$. End-tidal $\mathrm{Po}_{2}$ is maintained con- stant by the addition of $100 \%$ nitrogen to the inspired gas in amounts sufficient to prevent it rising during the ensuing hyperventilation. The relationship between $\mathrm{PACO}_{2}$ and minute ventilation is linear and the data are analyzed by least squares linear regression (9). The equation traditionally used to relate ventilation and $\mathrm{PACO}_{2}$ is as follows: $\mathrm{VE}_{E}=$ $\mathrm{S}\left(\mathrm{PACO}_{2}-\mathrm{B}\right)(10)$ where $\mathrm{B}$ is the extrapolated intercept on the abscissa ( $\mathrm{PAcO}_{2}$ axis) and $\mathrm{S}$ is the slope of the line expressed as change in ventilation per unit change in $\mathrm{PAcO}_{2}$. The non-steady-state procedure has been validated by Read (11) who demonstrated excellent agreement of slopes obtained during rising $\mathrm{PAcO}_{2}$ with those from a series of steady-state measurements. In the present study the rate of increase in $\mathrm{PAcO}_{2}$ of $1 \mathrm{~mm} \mathrm{Hg} / \mathrm{min}$ was considerably slower than the increase of $4-6 \mathrm{~mm} \mathrm{Hg} / \mathrm{min}$ employed by Read.

Hypoxic ventilatory drive on exercise. During two or three levels of steady-state submaximal treadmill exercise ventilation was measured while breathing firstly $100 \%\left(\mathrm{PI}_{\mathrm{O}_{2}}\right.$ $=625 \mathrm{~mm} \mathrm{Hg}$ ) oxygen and secondly $14 \%$ oxygen in nitrogen $\left(\mathrm{P}_{\mathrm{IO}_{2}}=88 \mathrm{~mm} \mathrm{Hg}\right)$. After $6 \mathrm{~min}$ of a given work load with the subject breathing $100 \%$ oxygen, the inspired air was switched to $14 \%$ oxygen and maintained for a further $6 \mathrm{~min}$. Ventilation was measured during the last minute of each period and $\mathrm{O}_{2}$ uptake during the last minute of the hypoxic period. The three points (or two points) for each subject at a given inspired oxygen fraction were analyzed by linear regression. The mean slopes for the group were obtained by averaging the regression coefficients and intercepts for each of the individuals in each group.

\section{RESULTS}

Hypoxic ventilatory drive at rest. A representative study from one subject in each group is shown in Fig. 1. Each point represents the mean for three successive breaths and the superimposed curves are derived from a nonlinear least squares fit of the data points. The goodness of fit was in all cases $P<0.005$ or better. Individual curves for all subjects in all groups are shown in Fig. 2 and the mean curves for each group are compared in Fig. 3 . The curve shape is measured by the parameter A such that a large value for $\mathrm{A}$ denotes a high hypoxic ventilatory drive. In the non-native residents of high altitude A averaged $77.1 \pm 19.6$ (SEM); this was less than half the value of $180.2 \pm 14.5$ observed in the low altitude controls $(P<0.05)$, indicating attenuation of hypoxic ventilatory drive (see Table I). A more striking degree of attenuation was seen in the high altitude natives in whom $\mathrm{A}$ averaged $17.4 \pm 4.5$, approximately one-tenth that of the control group $(P<0.01)$. The within group variance or heterogeneity of these hypoxic ventilatory responses curves was greater in the non-native group in comparison with that of natives and controls (see Fig. 2). It was found that this variation could be accounted for in large part by differences in time spent at high altitude (Fig. $4 a$ ). In subjects who had lived at high altitude for $5 \mathrm{yr}$ or less depression of hypoxic ventilatory drive was minimal while in those who had lived at high altitude for $25 \mathrm{yr}$ or longer, hypoxic ventilatory

Ventilatory Control during Chronic Hypoxia 187 

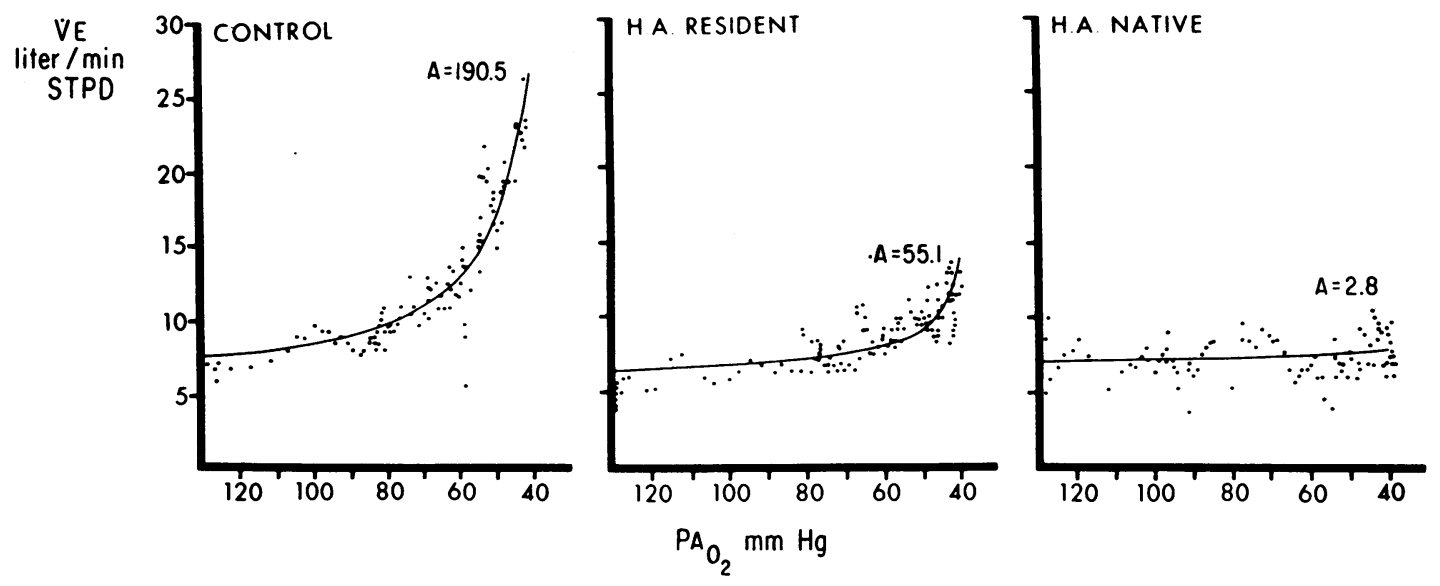

FIGURE 1 Single studies relating $\mathrm{VE}$ and $\mathrm{PAO}_{2}$ in a low altitude resident ( $\mathrm{R}$. Y.), high altitude resident (L. W.), and high altitude native (T. F.). Each point represents a mean value for three successive breaths, and the lines were obtained through least squares fit, $P<0.005$ in all cases.

drive was depressed to a degree similar to that seen in the high altitude native.

Hypercapnic ventilatory drive. Representative studies for one subject of each group are shown in Fig. 5. In both groups of high altitude dwellers there is a left shift of $\mathrm{VE}-\mathrm{PAco}_{2}$ lines indicated by a smaller value for the intercept, $\mathrm{B},(P<0.01)$ (see Table I). Slope of the $V_{E}-P_{A c o}$ lines in the non-native highlanders averaged $1.31 \pm 0.21$ compared with $2.02 \pm 0.22$ in the control group $(P<0.05)$. The slope $\mathrm{S}$ of the $\mathrm{VE}-\mathrm{PAco}_{2}$ lines is shown as a function of time at high altitude in Fig. $4 a$. The changes roughly paralleled those observed for hypoxic drive. In the high altitude natives the slope was even more depressed in comparison with the control group, averaging $1.06 \pm 0.15(P<0.01)$ (see Fig. 6).
Hypoxic ventilatory drive during exercise. This was studied in seven control subjects, six high altitude natives, and seven high altitude residents. Analysis of the data was based on the fact that ventilation increases as a linear function of oxygen uptake during submaximal exercise. For each subject ventilation was measured at three work levels-that is, three levels of oxygen uptake -while breathing $100 \%$ oxygen and while breathing $14 \%$ oxygen. Regression lines for $\mathrm{VE}_{\mathrm{E}}$ on $\mathrm{V}_{\mathrm{o}_{2}}$ of the form $\mathrm{VE}=\alpha+\beta \mathrm{VO}_{2}$ were computed for each subject for each of the two separate inspired oxygen concentrations. The parameters for these equations are listed in Table II.

Fig. $7 a$ shows that the mean lines for the control and the high altitude non-native residents were similar both during $100 \%$ and $14 \%$ oxygen breathing. However, the
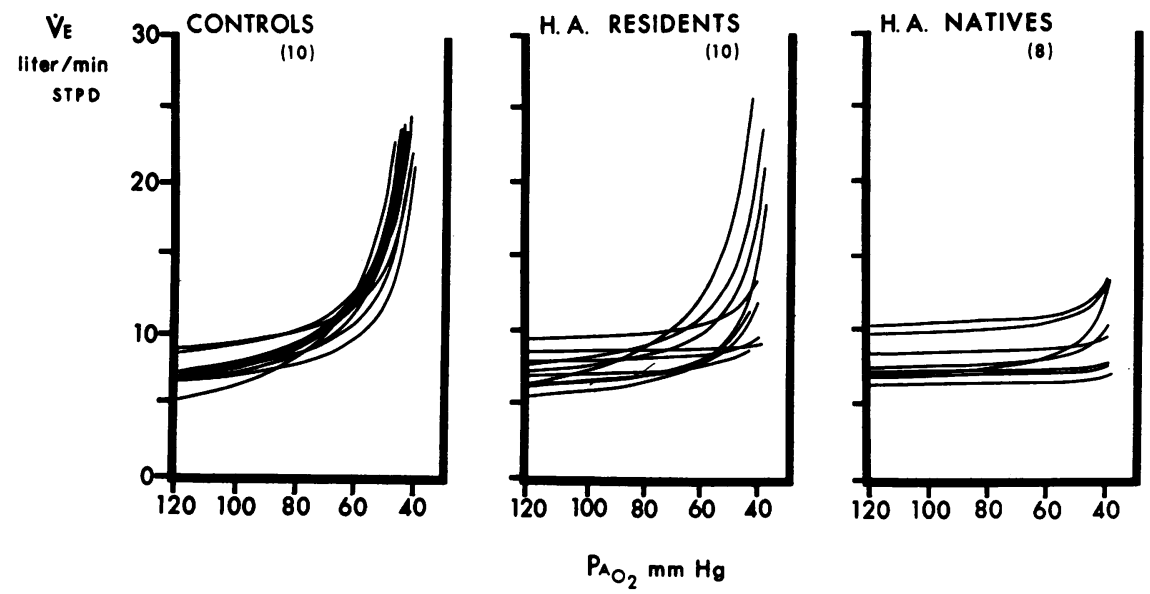

FIgure 2 Curves relating $\mathrm{VE}_{\mathrm{E}}$ and $\mathrm{PA}_{\mathrm{O}_{2}}$ for all individuals studied. Controls and high altitude natives demonstrate a rather homogenous format while the non-native high altitude residents show considerable heterogeneity overlapping controls on one hand and natives on the other. 
high altitude natives when contrasted with controls (Fig. $7 \mathrm{~b}$ ) breathed slightly less during exercise with $14 \%$ oxygen. A similar difference was also seen at the higher levels of oxygen uptake while breathing $100 \%$ oxygen.

Comparison of hypoxic drive during exercise between the three groups can be more easily assessed by examining the increase of exercising hyperpnea resulting from a decrease in inspired oxygen from $100 \%$ to $14 \%$. This relationship can be described for each group by the following equations obtained by subtraction.

$$
\begin{array}{ll}
\text { Controls VE } 14 \%-\text { VE } 100 \%=-7.5+0.0186 \mathrm{Vo}_{2} \\
\text { HAR VE } 14 \%-\text { VE } 100 \%=-10.8+0.0190 \mathrm{Vo}_{2} \\
\text { HAN VE } 14 \%-\mathrm{VE} 100 \%=-17.3+0.0223 \mathrm{Vo}_{o_{2}}
\end{array}
$$

These lines are shown in Fig. 8. By analysis of covariance the lines for high altitude residents did not differ from the controls $P<0.5$. In contrast the line for high altitude natives was different from control for both position being right-shifted $(P<0.05)$, and slope which was steeper $(P<0.05)$, the latter being due to the lower ventilation when breathing $100 \% \quad \mathrm{O}_{2}$. These findings indicate that in the high altitude native the ventilatory response to hypoxia is diminished at low work loads similar to the findings at rest, but at higher work loads the response approaches that of the controls.

\section{DISCUSSION}

This paper presents new information concerning three important areas relative to respiratory regulation. Firstly, chronic hypoxia beginning during adulthood results in depression of the ventilatory response to hypoxia at rest. Secondly, this change appears to be related to altered

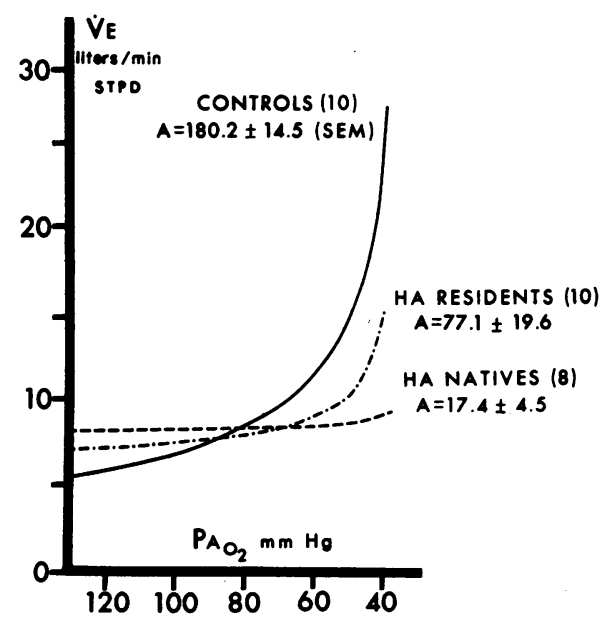

Figure 3 Mean curves relating $\mathrm{V}_{E}$ and $\mathrm{PA}_{\mathrm{O}_{2}}$ for each group of subjects. Hypoxic ventilatory drive is markedly reduced in the natives of high altitude $(P<0.01)$ and moderately depressed in the high altitude residents $(P<$ 0.05).
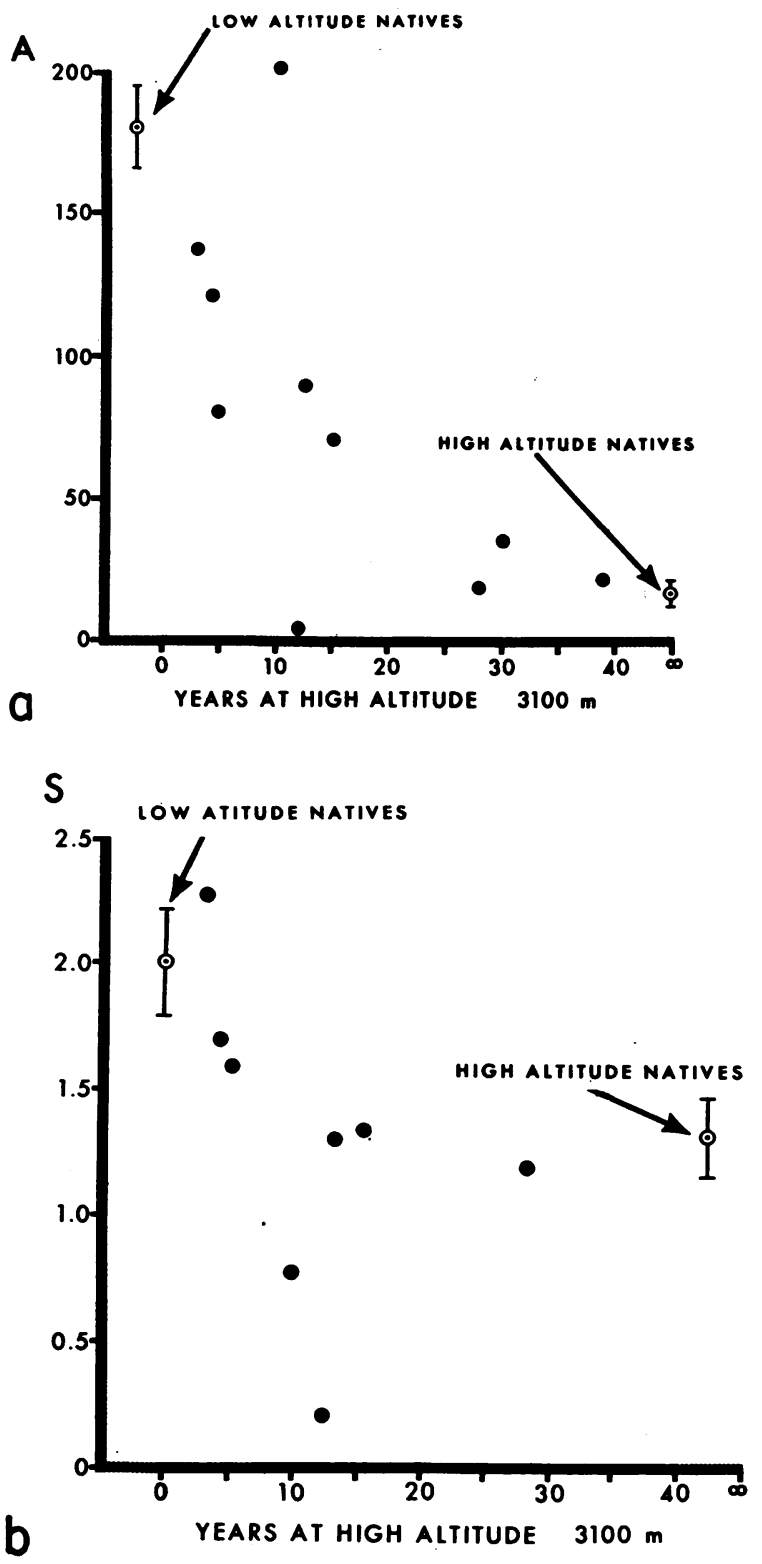

FIGURE $4(a)$ Effect of time spent at high altitude on hypoxic ventilatory drive as measured by the parameter $\mathrm{A}$. The data suggest that depression of hypoxic ventilatory drive is a function of time at altitude such that after 25 $\mathrm{yr}$ values resemble those of high altitude natives. $(b)$ Effect of time spent at high altitude on hypercapnic ventilatory drive as measured by $\mathrm{S}$, the slope of $\mathrm{VE}_{\mathrm{E}}-\mathrm{P}_{\mathrm{ACO}_{2}}$ lines.

peripheral chemoreceptor function. Lastly, the ventilatory response to hypoxia during exercise is well preserved in chronically hypoxic man suggesting that ventilatory responses to hypoxia during rest and exercise are separately mediated.

Several investigators, using diverse techniques, have measured a marked decrease in the ventilatory response 
TABLE I

Data on Controls, High Altitude Residents,

\begin{tabular}{|c|c|c|c|c|c|c|}
\hline & Age & $\mathrm{Ht}$ & wt & BSA & $\begin{array}{l}\text { Age of } \\
\text { arrival } \\
\text { at high } \\
\text { altitude }\end{array}$ & $\begin{array}{l}\text { Time } \\
\text { at high } \\
\text { altitude }\end{array}$ \\
\hline Controls & yr & $c m$ & $k g$ & $m^{2}$ & $y r$ & yr \\
\hline 1. E. B.-Q. & 33 & 175 & 74.1 & 1.90 & & \\
\hline 2. V. C. & 22 & 181 & 68.6 & 1.87 & & \\
\hline 3. R. F. G. & 45 & 180 & 71.0 & 1.91 & & \\
\hline 4. M. J. & 22 & 190 & 88.6 & 2.09 & & \\
\hline 5. R. McG. & 26 & 135 & 93.9 & 2.19 & & \\
\hline 6. M. R. & 23 & 180 & 105.5 & 2.25 & & \\
\hline 7. I. E.S. & 35 & 182 & 67.7 & 1.88 & & \\
\hline 8. B. U. & 30 & 182 & 67.7 & 1.88 & & \\
\hline 9. J. V. W. & 34 & 175 & 75.5 & 1.91 & & \\
\hline 10. R. Y. & 22 & 179 & 88.6 & 2.08 & & \\
\hline Mean & 29.2 & 180 & 80.1 & 2.00 & & \\
\hline SEM & 2.4 & 1 & 4.2 & 0.05 & & \\
\hline \multicolumn{7}{|c|}{ High altitude residents } \\
\hline 1. C. C. & 40 & 196 & 95.5 & 2.08 & 28 & 12 \\
\hline 2. R. C. & 39 & 165 & 73.2 & 1.89 & $\frac{1}{2}$ & 38.5 \\
\hline 3. J. F. & 44 & 172 & 65.9 & 1.78 & 31 & 13 \\
\hline 4. S. F. & 63 & 180 & 74.2 & 1.93 & 33 & 30 \\
\hline 5. R. K. & 59 & 177 & 75.9 & 1.91 & 31 & 28 \\
\hline 6. B. P. & 48 & 180 & 78.9 & 1.99 & 38 & 10 \\
\hline 7. R. Sh. & 39 & 183 & 103.2 & 2.26 & 36 & 3 \\
\hline 8. G. W. & 31 & 183 & 90.0 & 2.13 & 27 & 4 \\
\hline 9. L. W. & 47 & 177 & 82.7 & 2.01 & 32 & 15 \\
\hline 10. G. Z. & 25 & 183 & 95.5 & 2.19 & 20 & 5 \\
\hline Mean & 42.5 & 180 & 83.5 & 2.02 & & 16 \\
\hline SEM & 4.3 & 2.6 & 3.8 & 0.05 & & 4 \\
\hline \multicolumn{7}{|c|}{ High altitude natives } \\
\hline 1. G. D. & 42 & 180 & 70.9 & 1.90 & & \\
\hline 2. J. D. & 29 & 178 & 70.9 & 1.88 & & \\
\hline 3. R.F. & 39 & 174 & 98.2 & 2.12 & & \\
\hline 4. T. F. & 37 & 183 & 83.6 & 2.06 & & \\
\hline 5. F. L. & 35 & 203 & 94.5 & 2.32 & & \\
\hline 6. J. L. & 34 & 173 & 66.4 & 1.79 & & \\
\hline 7. R. St. & 56 & 175 & 74.5 & 1.90 & & \\
\hline 8. H. T. & 55 & 178 & 79.3 & 1.78 & & \\
\hline Mean & 41 & 181 & 79.8 & 1.97 & & \\
\hline SEM & 3 & 3 & 4.1 & 0.07 & & \\
\hline
\end{tabular}

to hypoxia in persons native to high altitude (1-3), and this is confirmed by the present study. Sorensen and Severinghaus (12) and Edelman, Lahiri, Braudo, Cherniack, and Fishman (13) have shown that in patients with cyanotic congenital heart disease hypoxic ventilatory drive is markedly reduced $(12,13)$. This finding clearly indicated that a nongenetic acquisition of attenuated hypoxic ventilatory drive may occur as a consequence of prolonged hypoxia, but it was believed that this could only happen when the exposure to hypoxia occurred at birth or in early infancy.

To date it has not been demonstrated that attenuation of hypoxic ventilatory drive occurs in adult man as a result of long-term exposure to hypoxia. There are several studies of hypoxic ventilatory drive in low altitude subjects during high altitude sojourns ranging from a few days to many weeks $(2,3,14,15)$. Most of these studies show no change in hypoxic ventilatory drive. 


\begin{tabular}{|c|c|c|c|c|c|c|c|}
\hline \multirow[b]{2}{*}{$\mathbf{N}$} & \multicolumn{2}{|c|}{$\begin{array}{l}\text { Hypoxic ventilatory drive } \\
\text { at rest } \\
\text { PACOz }^{\text {a }}\end{array}$} & \multirow[b]{2}{*}{ A } & \multirow[b]{2}{*}{$\dot{\mathrm{V}}_{\mathrm{E}_{0}}$} & \multicolumn{3}{|c|}{$\begin{array}{l}\text { Hypercapnic ventilatory } \\
\text { drive }\end{array}$} \\
\hline & Control & Hypoxia & & & $\mathrm{S}$ & B & $\mathrm{PAO}_{2}$ \\
\hline 7 & 36.1 & 35.0 & 159.7 & 5.3 & 2.54 & 27.7 & 60.7 \\
\hline 3 & 41.9 & 41.0 & 99.5 & 4.4 & 0.97 & 30.7 & 80.6 \\
\hline 4 & 39.0 & 38.7 & 194.8 & 4.9 & 1.13 & 28.3 & 68.9 \\
\hline 2 & 32.2 & 31.9 & 169.6 & 5.0 & 1.43 & 29.5 & 69.5 \\
\hline 3 . & 39.1 & 37.8 & 170.1 & 6.2 & 3.01 & 34.8 & 71.7 \\
\hline 2 & 33.1 & 33.8 & 176.9 & 4.8 & 2.14 & 28.2 & 64.2 \\
\hline 5 & 32.9 & 32.7 & 142.5 & 5.8 & 1.52 & 27.1 & 64.2 \\
\hline 4 & 38.2 & 38.2 & 272.2 & 4.3 & 2.58 & 34.2 & 74.2 \\
\hline 7 & 36.8 & 35.6 & 217.2 & 2.6 & 2.48 & 35.0 & 73.9 \\
\hline \multirow[t]{3}{*}{2} & 36.1 & 34.8 & 199.8 & 5.0 & 2.41 & 31.9 & 70.2 \\
\hline & 36.5 & 36.0 & 180.2 & 4.8 & 2.02 & 30.7 & 69.8 \\
\hline & 1.0 & 0.9 & 14.5 & 0.3 & 0.22 & 1.0 & 1.8 \\
\hline 2 & 35.8 & 37.0 & 1.8 & 8.1 & 0.23 & 14.4 & 83.5 \\
\hline 2 & 31.5 & 31.5 & 21.4 & 6.3 & - & - & - \\
\hline 2 & 25.8 & 25.5 & 89.3 & 4.9 & 1.30 & 23.6 & 58.9 \\
\hline 2 & 41.7 & 41.3 & 34.6 & 7.8 & - & - & - \\
\hline 2 & 30.3 & 30.2 & 19.2 & 7.4 & 1.20 & 25.8 & 63.0 \\
\hline 3 & 32.2 & 32.0 & 199.2 & 4.0 & 0.85 & 21.4 & 63.6 \\
\hline 2 & 30.5 & 30.2 & 136.9 & 6.2 & 2.27 & 29.2 & 65.2 \\
\hline 2 & 29.3 & 29.3 & 119.7 & 6.0 & 1.70 & 25.5 & 61.1 \\
\hline 2 & 33.5 & 34.1 & 69.6 & 5.5 & 1.33 & 25.6 & 64.8 \\
\hline \multirow[t]{3}{*}{3} & 32.4 & 32.6 & 79.3 & 4.9 & 1.58 & 30.5 & 70.6 \\
\hline & 32.3 & 32.4 & 77.1 & 6.1 & 1.31 & 24.5 & 66.3 \\
\hline & 1.3 & 1.4 & 19.6 & 0.4 & 0.21 & 1.8 & 2.7 \\
\hline 1 & 30.1 & 29.5 & 42.9 & 6.5 & 0.94 & 22.2 & 59.7 \\
\hline 2 & 31.4 & 30.8 & 28.3 & 7.2 & 1.57 & 28.3 & 66.2 \\
\hline 3 & 32.8 & 33.4 & 11.5 & 10.1 & 1.64 & 26.9 & 66.8 \\
\hline 2 & 32.1 & 32.3 & 14.4 & 7.0 & 0.77 & 24.4 & 68.2 \\
\hline 2 & 35.7 & 36.0 & 18.3 & 9.9 & 1.45 & 30.8 & 66.0 \\
\hline 1 & 32.7 & 32.7 & 4.0 & 7.1 & 1.01 & 27.5 & 65.1 \\
\hline 2 & 29.9 & 30.5 & 15.1 & 5.9 & 0.53 & 17.4 & 61.1 \\
\hline \multirow[t]{3}{*}{2} & 33.4 & 34.1 & 5.0 & 8.0 & 0.60 & 19.8 & 73.0 \\
\hline & 32.3 & 32.4 & 17.4 & 7.7 & 1.06 & 24.7 & 65.8 \\
\hline & 0.7 & 0.8 & 4.5 & 0.6 & 0.15 & 1.6 & 1.5 \\
\hline
\end{tabular}

Indeed, Forster et al. (16) found that the ventilatory response to hypoxia actually increased during 45 days at $3100 \mathrm{~m}$. There are only four studies which deal with the status of hypoxic ventilatory drive in truly longterm non-native residents of high altitude. Chiodi (17) found that minute ventilation was lower and $\mathrm{PAcos}_{2}$ higher in long-term residents than in newcomers at 3990 $\mathrm{m}$ and $4515 \mathrm{~m}$ in the Andes. $\mathrm{He}$ also found that the decrease in ventilation produced by oxygen administra- tion was diminished in subjects who had lived for $6 \mathrm{yr}$ or longer at those altitudes. These findings suggested that hypoxic ventilatory drive might be attenuated in long-term residents of high altitude, but all of these subjects were born on the Andean altiplano and hence were natives of altitudes greater than $3000 \mathrm{~m}$. Thus these findings may have actually been due to birth at high altitude rather than to exposure to even higher altitudes during adulthood. Sorensen and Severinghaus (15) re- 

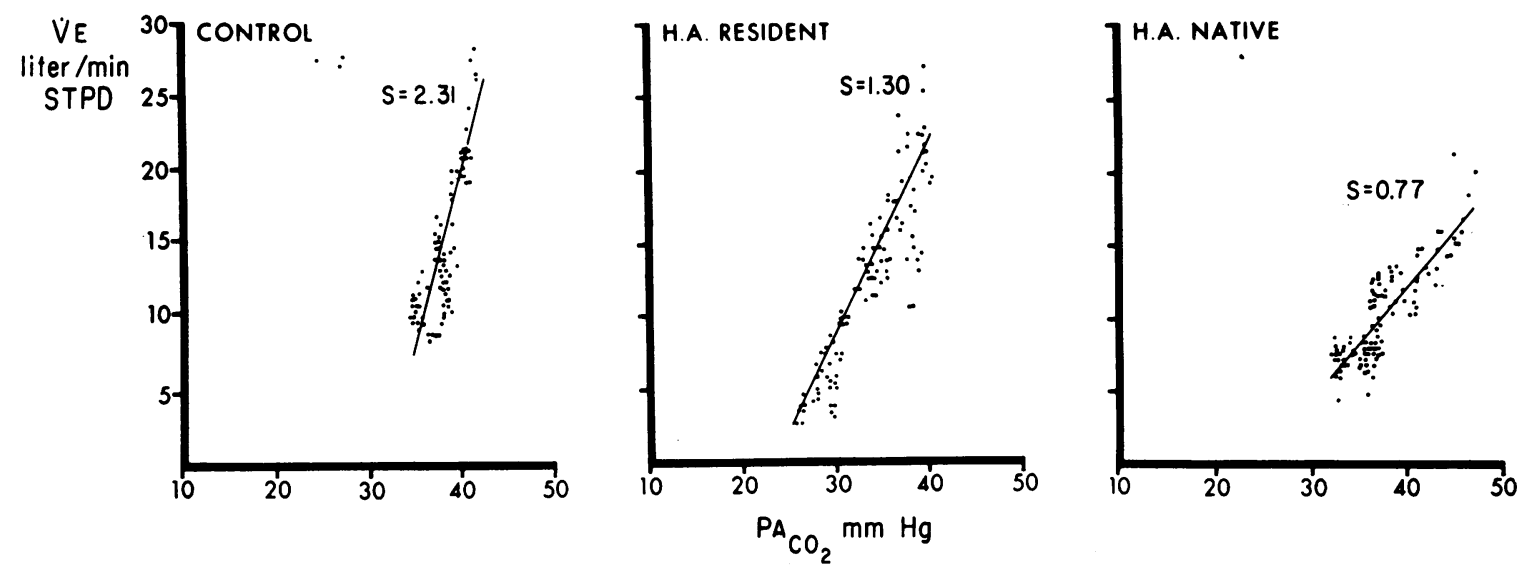

FIgure 5 Individual studies for isoxic $\mathrm{VE}_{\mathrm{E}}-\mathrm{PACO}_{2}$ relationship for a control subject (R. Y.), high altitude resident (J. F.), and high altitude native (T. F.) are shown.

ported that hypoxic ventilatory drive remained unchanged in subjects living for 2 months to $12 \mathrm{yr}$ at 4360 $\mathrm{m}$ and failed to find a relationship between hypoxic drive and time at high altitude within this group. The mean period of high altitude residence in their group averaged only $2.5 \mathrm{yr}$ and only one subject had lived at high altitude for more than $6 \mathrm{yr}$. As the authors themselves speculated their subjects may not have been exposed to high altitude for a long enough period for significant attenuation to have occurred. Indeed the results of the present study indicate that lengthy exposure to hypoxia is required to produce profound alteration in hypoxic drive. Similarily Lahiri, Kao, Velasquez, Martinez, and Pezzia (18) studied a group of eight long-term high altitude

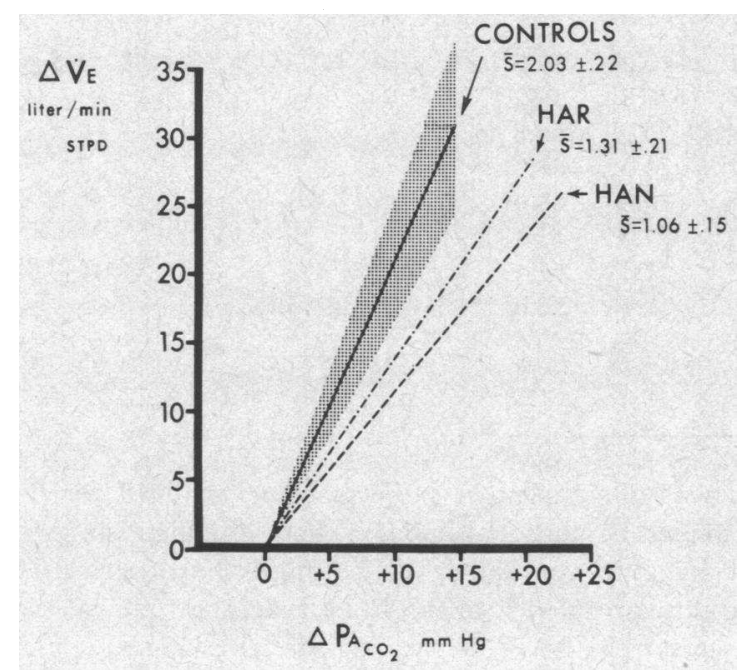

FIgURE 6 Mean isoxic $\mathrm{VE}-\mathrm{PAcO}_{2}$ lines for each group. Data are plotted as differences of ventilation and alveolar $\mathrm{PCO}_{2}$ from control levels. The shaded area about the control encompasses \pm 2 SEM. residents of which only two had lived more than $4 \mathrm{yr}$ at high altitude and found no depression of hypoxic drive. In both of these studies ventilatory response to hypoxia was estimated from the change slope of the $V_{E}-$ $\mathrm{Pco}_{2}$ lines resulting from alterations of $\mathrm{P}_{\mathrm{O}_{2}}$ and a total of only six to eight data points were available for each individual. In the present study a single curve relating $\mathrm{VE}$ and $\mathrm{PAO}_{2}$ was derived from $100-150$ data points and at least two curves were measured on each individual. Perhaps for this reason the studies referred to above showed large scatter in the control data and may not have been capable of detecting the intermediate degrees of depression of hypoxic drive which were found in many of the non-native residents of high altitude.

Depression of hypercapnic ventilatory drive in both native and non-native residents of high altitude was observed and in the latter group could be related to time at altitude in a fashion similar to the depression of hypoxic drive. This was also found in the residents of high altitude studied by Chiodi (17). In contrast, several investigators have failed to find any alteration in hypercapnic ventilatory drive in natives of high altitude (1, $2,16,18)$. Reasons for this discrepancy are not clear. In the present study the $\mathrm{VE}_{\mathrm{E}}-\mathrm{PAco}_{2}$ curves were performed at a $\mathrm{PAO}_{2}$ of about $70 \mathrm{~mm} \mathrm{Hg}$ and it could be argued that at this oxygen tension there is sufficient hypoxic drive to effect the slope of these lines through $\mathrm{O}_{2}-\mathrm{CO}_{2}$ interaction. If true, the diminished hypoxic drive in highlanders could reduce the response to $\mathrm{CO}_{2}$ as measured by the slope of the $\mathrm{VE}_{\mathbf{E}}-\mathrm{PAco}_{2}$ lines. However, data from the study of Cormack, Cunningham, and Gee (10) as well as that of Lahiri et al. (18) indicate that at a $\mathrm{PAo}_{2}$ of $70 \mathrm{~mm} \mathrm{Hg}$ the effect of hypoxic drive on the slope of the $\mathrm{VE}-\mathrm{P}_{\mathrm{Aco}}$ curve is much too small to account for the differences seen in our studies. In our own experience we cannot measure a slope differ- 
TABLE II

Parameters of the Regression Equation $\dot{\mathrm{V}} \mathrm{E}=\alpha+\beta \mathrm{Vo}_{2}$ while Breathing $100 \%$ and $14 \%$ Oxygen during Exercise

\begin{tabular}{|c|c|c|c|c|}
\hline & \multicolumn{2}{|c|}{$100 \% \mathrm{O}_{2}$} & \multicolumn{2}{|c|}{$14 \% \mathrm{O}_{2}$} \\
\hline & $\boldsymbol{\alpha}$ & $\beta$ & $\alpha$ & $\beta$ \\
\hline \multicolumn{5}{|l|}{ Controls } \\
\hline 1. E. B.-Q. & 0.5 & 0.0239 & -3.3 & 0.0361 \\
\hline 2. v. C. & -5.0 & 0.0393 & -13.7 & 0.0630 \\
\hline 3. R. F. G. & 6.4 & 0.0244 & -4.0 & 0.0495 \\
\hline 4. R. McG. & 2.9 & 0.0205 & -2.1 & 0.0300 \\
\hline 5. I. E. S. & -0.5 & 0.0236 & -9.4 & 0.0380 \\
\hline 6. B. U. & 2.0 & 0.0244 & -0.6 & 0.0357 \\
\hline 7. J. V. W. & 2.4 & 0.0315 & -11.1 & 0.0656 \\
\hline Mean & 1.2 & 0.0268 & -6.3 & 0.0454 \\
\hline SEM & 1.3 & 0.0024 & 2.4 & 0.0053 \\
\hline \multicolumn{5}{|c|}{ High altitude residents } \\
\hline 1. C. C. & 8.5 & 0.0174 & -0.5 & 0.0284 \\
\hline 2. R. C. & 9.5 & 0.0268 & -4.0 & 0.0567 \\
\hline 3. S. F. & 7.7 & 0.0203 & -2.2 & 0.0374 \\
\hline 4. R. J. & 12.9 & 0.0262 & 0.3 & 0.0441 \\
\hline 5. B. P. & 1.4 & 0.0224 & -2.0 & 0.0406 \\
\hline 6. L.W. & 10.7 & 0.0181 & -0.1 & 0.0362 \\
\hline 7. G. Z. & 12.1 & 0.0171 & -4.2 & 0.0378 \\
\hline Mean & 9.0 & 0.0212 & -1.8 & 0.0402 \\
\hline SEM & 1.4 & 0.0015 & 0.7 & 0.0033 \\
\hline \multicolumn{5}{|c|}{ High altitude natives } \\
\hline 1. J. D. & 16.5 & 0.0187 & 0.6 & 0.0403 \\
\hline 2. R F. & 11.2 & 0.0245 & -22.0 & 0.0604 \\
\hline 3. T. F. & 6.3 & 0.0218 & -10 & 0.0412 \\
\hline 4. J. L. & 8.3 & 0.0167 & 1 & 0.0307 \\
\hline 5. R. St. & 16.5 & 0.0114 & -2.2 & 0.0348 \\
\hline 6. H. T. & 16.1 & 0.10166 & 3.5 & 0.0364 \\
\hline Mean & 12.5 & 0.0183 & -4.8 & 0.0406 \\
\hline SEM & 1.9 & 0.0019 & 4.0 & 0.0042 \\
\hline
\end{tabular}

ence between curves done at $\mathrm{PAO}_{2}$ of 150 and those done at $70 \mathrm{~mm} \mathrm{Hg}$.

The finding that the ventilatory responses to both hypoxia and hypercapnia are attenuated during chronic exposure to hypoxia provides important clues regarding the role of the peripheral chemoreceptors in these effects. It is generally accepted that the peripheral chemoreceptors are responsible for virtually all of the resting hypoxic drive and roughly half of the hypercapnic drive in man $(19,20)$. In the present studies we found that in the high altitude natives and in the non-native with longest residence at altitude hypoxic drive was reduced almost to zero, while hypercapnic drive averaged about one-half that of the low altitude controls. This pattern resembles so closely that which would be expected to result from failure of peripheral chemoreceptor function that we strongly suspect that the changes observed in our high altitude subjects are due to some alteration either in the peripheral chemoreceptor itself or interference with the integration of chemoreceptor impulses within the central nervous system. The study of Sorensen and Cruz (21) which demonstrated in high altitude natives a decreased ventilatory response to a single breath
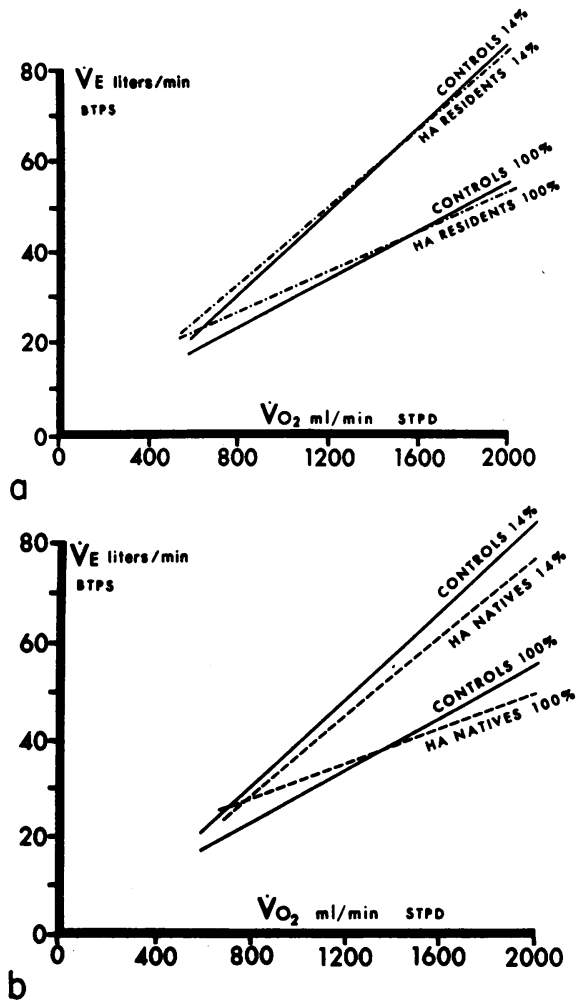

FIGURE 7 Minute ventilation in relation to oxygen uptake during exercise for two levels of inspired oxygen. Controls are compared with $(a)$ high altitude residents and $(b)$ high altitude natives.

of hypercapnic gas mixtures strongly supports this concept, as the ventilatory response to very brief $\mathrm{CO}_{2}$ stimuli is thought to be a relatively specific qualitative test of chemoreceptor responsiveness. Furthermore, the observation of gross enlargement of the carotid bodies which has been observed both in man at high

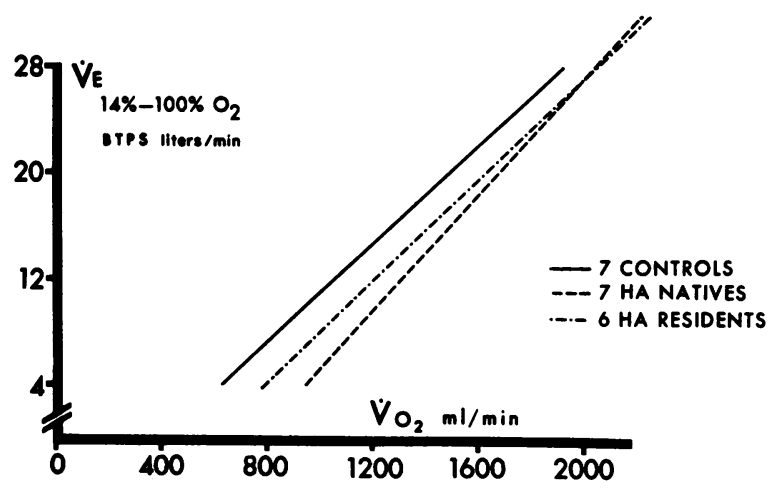

FIGURE 8 Change in $\nabla E$ due to decreasing inspired $\mathrm{O}_{2}$ concentration from 100 to $14 \%$ in relation to $\mathrm{O}_{2}$ uptake for each group. At lower work loads the breathing of the high altitude native is less stimulated by hypoxia than the controls, but at higher work loads this difference disappears.

Ventilatory Control during Chronic Hypoxia 
altitude (22) and in patients with chronic airway obstruction (23) supports the notion that an alteration in this system has occurred although the precise implications of these findings are not known.

During exercise the findings in the high altitude subjects were quite different than at rest, the response of ventilation to superimposed hypoxia being as great as that seen in the low altitude controls. There is much uncertainty regarding the nature of the mechanisms which control breathing during exercise and the role of the chemoreceptors is a matter of controversy. Typically during exercise, alterations in arterial blood gases do not appear sufficient to account for significant chemoreceptor stimulation (24). However, when inspired $\mathrm{P}_{02}$ is altered abruptly during exercise ventilation changes so rapidly that a reflex mediated by the peripheral chemoreceptors has been suggested (25). This in turn has led to speculation that the responsiveness of the carotid body is enhanced in some fashion during exercise so that the chemoreceptors are rendered highly responsive to stimuli which would be inconsequential at rest (25). Our findings suggest that there is a marked discrepancy between hypoxic drive at rest, which is presumably mediated by peripheral chemoreceptors, and hypoxic response during exercise. This dissociation of resting and exercise hypoxic drive suggests that different control systems are involved. Similarly we have recently reported evidence of diminished peripheral chemoreceptor function in conditioned athletes in whom the ventilatory response to hypoxia during exercise is unimpaired (26). Thus it would appear either the peripheral chemoreceptors are unimportant during exercise or that chemoreceptors which function poorly at rest may be readily activated during exercise.

The fact that attenuated chemoreceptor function can be acquired as a consequence of prolonged exposure to hypoxia undoubtedly has relevance to the control of breathing in clinical situations involving chronic hypoxia. Diminished hypoxic ventilatory drive has been described in patients with cyanotic congenital heart disease $(12,13)$ and Flenley and Millar (27) have suggested that the same may be true of certain patients with chronic airways obstruction. In some patients with chronic airway obstruction dyspnea is remarkably absent despite severe derangement of arterial blood gases. Such patients are sometimes referred to as "nonfighters" or "blue bloaters" (28). In such patients the pathology usually is that of extensive bronchitis with relatively little emphysematous change (29). It appears that this pathology results in greater shunting of venous blood producing arterial hypoxemia which is refractory to increases in ventilation (30). The resulting chronic hypoxemia could in turn lead to a loss of ventila- tory drive as in the high altitude resident and may explain why such patients become nonfighters.

\section{ACKNOWLEDGMENTS}

We wish to express our gratitude to the citizens of Leadville, Colo., who supported this work with enthusiasm as they have done so often in the past.

Dr. Weil is the recipient of an Established Investigatorship of the Colorado Heart Association, Dr. Byrne-Quinn is the recipient of a Wellcome Research Travel Grant and a fellowship from the Colorado Heart Association, and Dr. Grover is the recipient of Career Development Award HE 29,237 from the National Institutes of Health. This work supported in part by U. S. Army Contract No DA-49-193-MD-2227, Research and Training Grant RT-10 from the Social and Rehabilitation Service Section Department of Health, Education, and Welfare, Research Grant No. HE-03191 from the U. S. Public Health Service, and by research grants from the American Thoracic Society and Council for Tobacco Research-U. S. A.

\section{REFERENCES}

1. Severinghaus, J. W., C. R. Bainton, and A. Carcelen. 1966. Respiratory insensitivity to hypoxia in chronically hypoxic man. Resp. Physiol. 1 : 308.

2. Milledge, J. S., and S. Lahiri. 1967. Respiratory control in lowlanders and Sherpa highlanders at altitude. Resp. Physiol. 2: 310 .

3. Lefrancois, R., H. Gautier, and P. Pasquis. 1968. Ventilatory oxygen drive in acute and chronic hypoxia. Resp. Physiol. 4: 217.

4. Weil, J. V., E. Byrne-Quinn, I. E. Sodal, W. O. Friesen, B. Underhill, G. F. Filley, and R. F. Grover. 1970. Hypoxic ventilatory drive in normal man. J. Clin. Invest. 49: 1061.

5. Weil, J. V., I. E. Sodal, and R. P. Speck. 1967. A modified fuel cell for the analysis of oxygen concentration of gases. J. Appl. Physiol. 23 : 419.

6. Sodal, I. E., R. R. Bowman, and G. F. Filley. 1968. A fast response oxygen analyzer with high accuracy for respiratory gas measurement. J. Appl. Physiol. 25: 181.

7. Lloyd, B. B., M. G. M. Jukes, and D. J. C. Cunningham. 1958. The relation between alveolar oxygen pressure and the respiratory response to carbon dioxide in man. Quart. J. Exp. Physiol. 43: 214.

8. Burnette, W. A., and C. S. Roberts. 1967. NLLSQ-A Fortran IV nonlinear least squares fitting program. Memorandum Bell Telephone Laboratories.

9. Sokal, R. R., and F. J. Rohlf. 1969. Biometry; The Principles and Practice of Statistics in Biological Research. W. H. Freeman \& Company, San Francisco.

10. Cormack, R. S., D. J. C. Cunningham, and J. B. L. Gee. 1957. The effect of carbon dioxide on the respiratory response to want of oxygen in man. Quart. J. Exp. Physiol. 42: 303.

11. Read, D. J. C. 1967. A clinical method of assessing the ventilatory response to carbon dioxide. Aust. Ann. Med. $16: 20$.

12. Sorensen, S. C., and J. W. Severinghaus. 1968. Respiratory insensitivity to acute hypoxia persisting after correction of tetralogy of Fallot. J. Appl. Physiol. 25: 221.

13. Edelman, N. H., S. Lahiri, L. Braudo, N. S. Cherniack, and A. P. Fishman. 1970. The blunted ventilatory response to hypoxia in cyanotic congenital heart disease. N. Engl. J. Med. 282: 405. 
14. Michel, C. C., and J. S. Milledge. 1963. Respiratory regulation in man during acclimatization to high altitude. J. Physiol. 168 : 631.

15. Sorensen, S. C., and J. W. Severinghaus. 1968. Respiratory sensitivity to acute hypoxia in man born at sea level living at high altitude. J. Appl. Physiol. 25 : 211.

16. Forster, H. V., J. A. Dempsey, M. L. Birnbaum, W. G. Reddan, J. S. Thoden, R. F. Grover, and J. Rankin. 1969. Comparison of ventilatory responses to hypoxic and hypercapnic stimuli in altitude-sojourning lowlanders, lowlanders residing at altitude and native altitude residents. Fed. Proc. 28: 1274.

17. Chiodi, H. 1957. Respiratory adaptations to chronic high altitude hypoxia. J. Appl. Physiol. 10: 81 .

18. Lahiri, S., F. F. Kao, T. Velasquez, C. Martinez, and W. Pezzia. 1969. Irreversible blunted respiratory sensitivity to hypoxia in high altitude natives. Resp. Physiol. 6: 360 .

19. Dejours, P. 1962. Chemoreflexes in breathing. Physiol. Rev. 42: 335 .

20. Sorensen, S. C., and J. W. Severinghaus. 1968. Irreversible respiratory insensitivity to acute hypoxia in man born at high altitude. J. Appl. Physiol. 25: 217.

21. Sorensen, S. C., and J. C. Cruz. 1969. Ventilatory response to a single breath of $\mathrm{CO}_{2}$ in $\mathrm{O}_{2}$ in normal man at sea level and high altitude. J. Appl. Physiol. 27: 186.

22. Arias-Stella, J. 1969. Human carotid body at high altitudes. Amer. Ass. Pathol. Bacteriol. 150. (Abstr.)
23. Heath, D., C. Edwards, and P. Harris. 1970. Post mortem size and structure of the human carotid body: its relation to pulmonary disease and cardiac hypertrophy, Thorax. 25: 129.

24. Comroe, J. H., Jr., R. E. Forster II, A. B. Dubois, W. A. Briscoe, and E. Carlsen. 1962. The Lung. Year Book Medical Publisher, Inc., Chicago. 2nd edition.

25. Cunningham, D. J. C., D. Spurr, and B. B. Lloyd. 1968. The drive to ventilation from arterial chemoreceptors in hypoxic exercise. In Arterial Chemoreceptors. R. W. Torrance, editor. Blackwell Scientific Publications, Oxford. 301-323.

26. Byrne-Quinn, E., J. V. Weil, I. E. Sodal, G. F. Filley, and R. F. Grover. Ventilatory control in the athlete. J. Appl. Physiol. In press.

27. Flenley, D. C., and J. S. Millar. 1967. Ventilatory response to oxygen and carbon dioxide in chronic respiratory failure. Clin. Sci. 33: 319 .

28. Robin, E. D., and R. P. O'Neill. 1963. The fighter versus the nonfighter: control of ventilation in chronic obstructive pulmonary disease. Arch. Environ. Health. 7: 125.

29. Mitchell, R. S., S. F. Ryan, T. L. Petty, and G. F. Filley. 1966. The significance of morphologic chronic hyperplastic bronchitis. Amer. Rev. Resp. Dis. 93: 720.

30. Filley, G. F., H. J. Beckwitt, J. T. Reeves, and R. S. Mitchell. 1968. Chronic obstructive bronchopulmonary disease. II. Oxygen transport in two clinical types. Amer. J. Med. 44: 26. 